\title{
Correction to: Physical Exercise as a Modulator of Vascular Pathology and Thrombin Generation to Improve Outcomes After Traumatic Brain Injury
}

\author{
Willian Link Papalia ${ }^{1,2} \cdot$ Alexandre Seixas Nascimento ${ }^{2} \cdot$ Gokul Krishna $^{3}$ Núbia Broetto ${ }^{1,2,4} \cdot$ Ana Flavia Furian $^{5}$. \\ Mauro Schneider Oliveira ${ }^{5}$ Luiz Fernando Freire Royes ${ }^{1,2} \cdot$ Michele Rechia Fighera $^{1,2,4}$
}

Published online: 21 January 2022

๑) Springer Science+Business Media, LLC, part of Springer Nature 2021

\section{Correction to: Molecular Neurobiology}

https://doi.org/10.1007/s12035-021-02639-9

In the original manuscript, the author's sure name for "Gokul Krishna" is incorrect. The name "Krishnan" should be "Krishna" without "n" at the end.

The original paper has been corrected.

Publisher's Note Springer Nature remains neutral with regard to jurisdictional claims in published maps and institutional affiliations.

The original article can be found online at https://doi.org/10.1007/ s12035-021-02639-9.

Michele Rechia Fighera

mrfighera@yahoo.com.br

1 Center in Natural and Exact Sciences, Graduate Program in Biological Sciences: Toxicological Biochemistry, Federal University of Santa Maria, Santa Maria, RS, Brazil

2 Physical Education and Sports Center, Department of Sports Methods and Techniques, Exercise Biochemistry Laboratory (BIOEX), Federal University of Santa Maria, Santa Maria, RS, Brazil

3 Department of Child Health, University of Arizona College of Medicine-Phoenix, Phoenix, AZ, USA

4 Health Sciences Center, Department of Neuropsychiatry, Laboratory of Experimental and Clinical Neuropsychiatry, Federal University of Santa Maria, Santa Maria, RS 97105-900, Brazil

5 Health Sciences Center, Graduate Program in Pharmacology, Federal University of Santa Maria, Santa Maria, RS, Brazil 